\title{
Ivermectin efficacy against Biomphalaria, intermediate host snail vectors of Schistosomiasis
}

\author{
Naftale Katz ${ }^{1}$, Neusa Araújo ${ }^{1}$, Paulo Marcos Zech Coelho ${ }^{1}$, Carlos Medicis Morel ${ }^{2}$, Ana Rosa Linde-Arias ${ }^{2}$, \\ Takeshi Yamada ${ }^{3,4}$, Yuki Horimatsu ${ }^{4}$, Koh Suzuki ${ }^{4}$, Toshiaki Sunazuka ${ }^{3,4}$ and Satoshi Ömura ${ }^{3}$
}

The impact of ivermectin on adult snails of the genus Biomphalaria (B. glabrata, B. tenagophila and B. straminea), B. glabrata infected with Schistosoma mansoni, snail egg-masses cercariae and miracidia, as well as on guppy fish (Poecilia reticulata) was examined and evaluated. Biomphalaria snails, egg-masses, parasite stages and guppies were all exposed to different concentrations of ivermectin for $24 \mathrm{~h}$, followed by regular observations of mortality. The calculated lethal doses of ivermectin were around an $\mathrm{LD}_{50}$ of $0.03 \mu \mathrm{g} \mathrm{ml}-1$, and an $\mathrm{LD}_{90}$ of $0.3 \mu \mathrm{g} \mathrm{m} \mathrm{I}^{-1}$ for the three species of snails. Specimens of $B$. glabrata actually shedding parasite cercariae all died when exposed to ivermectin at a concentration of a mere $0.01 \mu \mathrm{g} \mathrm{ml}-1$. Ivermectin $B_{1 a}$, the major (80\%) component of commercially available ivermectin, proved to be inactive, and it was the minor (20\%) component, ivermectin $\mathrm{B}_{1 \mathrm{~b}}$, which caused snail death. Snail egg-masses were not affected, even at the highest concentration of $100 \mu \mathrm{g} \mathrm{ml}^{-1}$. With respect to $S$. mansoni parasite stages, $0.2 \mu \mathrm{g} \mathrm{ml} \mathrm{m}^{-1}$ ivermectin killed $50 \%$ of cercariae and miracidia within five minutes, rising to $90 \%$ after $30 \mathrm{~min}$. Mortality of guppy fish within $24 \mathrm{~h}$ of exposure to ivermectin at concentrations of $0.5 \mu \mathrm{g} \mathrm{ml}^{-1}$ and $0.01 \mu \mathrm{g} \mathrm{ml}-1$, were $100 \%$ and $30 \%$, respectively. The concentration of $0.01 \mu \mathrm{g} \mathrm{ml}-1$ that killed Schistosoma mansoni-infected snails only caused $30 \%$ mortality in guppy fish. Ivermectin can be considered a promising molluscicide, especially as it is more potent against infected snails than uninfected ones, although it has no impact on egg-masses. Ivermectin and its derivatives could be explored in the search for a new agent to help control schistosomiasis transmission.

The Journal of Antibiotics (2017) 70, 680-684; doi:10.1038/ja.2017.31; published online 15 March 2017

\section{INTRODUCTION}

Schistosomiasis is a widespread tropical parasitic disease caused by infection with trematode worms of the genus Schistosoma. People become infected when larval forms (cercaria) of the parasite emerge from infected freshwater snails and penetrate human skin that comes into contact with infested water. Some 258 million people worldwide were treated in 2014 and, in terms of the detrimental impact on human health, schistosomiasis ranks second behind malaria. A continuous cycle of infection and re-infection occurs where sanitation is unsatisfactory or absent, where hygiene is poor and where exposure to infective water sources is unavoidable. ${ }^{1}$

The life cycle of one disease-causing parasite (Schistosoma mansoni) requires transmission through an intermediate host, notably susceptible snail species of the genus Biomphalaria. In Brazil, three species are involved in transmission of cercaria: B. glabrata, B. tenagophila and $B$. straminea, with B. glabrata being recognized as the main vector throughout South America. Early-stage worm miracidia infect the freshwater snails, eventually developing into cercariae, which exit the snails into water to penetrate human skin. Several steps are necessary to control schistosomiasis transmission, including curative and preventive chemotherapy, sanitary education, provision of basic sanitation and action to combat snails involved in the transmission cycle. Due to a variety of factors, including cost-effectiveness, attempts to control snails is now recommended only in special cases and as a complementary feature, for example, when there is a localized outbreak of acute cases or when high rates persist even with periodic drug treatment of the population at risk. $^{2}$

Niclosamide (Bayluscide), a compound recommended by the World Health Organization (WHO), is the most effective molluscicide for killing intermediate host snails, as it causes the least amount of damage to the environment and to human health in comparison with other inorganic or synthetic molluscicides. However, it has several disadvantages: it is comparatively expensive, deployment costs are also high due to the need for repeated applications, it can cause environmental damage and its impact is only temporary. ${ }^{2}$ There is also a possibility of snails developing resistance to niclosamide, all of which illustrates the need for a better alternative, one that is less expensive, more effective, biodegradable, environmentally safe, easy to apply and that is widely available.,4

${ }^{1}$ Centro de Pesquisas René Rachou/Fiocruz, Belo Horizonte, Minas Gerais, Brazil; ${ }^{2}$ National Institute for Science and Technology on Innovation on Neglected Diseases (INCT/IDN), Center for Technological Development in Health (CDTS), Oswaldo Cruz Foundation (Fiocruz), Rio de Janeiro, RJ, Brazil; ${ }^{3}$ Kitasato Institute for Life Sciences, Kitasato University, Tokyo, Japan and ${ }^{4}$ Graduate School of Infection Control Sciences, Kitasato University, Tokyo, Japan

Correspondence: Dr N Katz, Centro de Pesquisas René Rachou/Fiocruz, Belo Horizonte, Minas Gerais 30190-002, Brazil.

E-mail: nkatz@cpqrr.fiocruz.br

or Professor T Sunazuka or Professor S Ōmura, Kitasato Institute for Life Sciences, Kitasato University, Tokyo 108-8641, Japan.

E-mail: sunazukatoshiaki@yahoo.co.jp or omuras@insti.kitasato-u.ac.jp

Received 5 October 2016; revised 30 January 2017; accepted 31 January 2017; published online 15 March 2017 


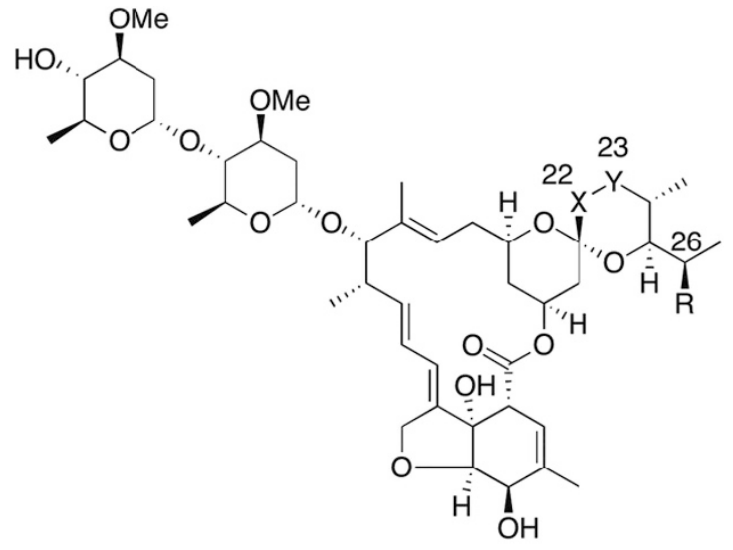

Ivermectin : mixture of dihydro derivatives of

$$
\mathrm{B}_{1 \mathrm{a}}(\mathbf{1})\left[\mathrm{R}=\mathrm{Et} ; \mathrm{X}-\mathrm{Y}=\mathrm{H}_{2} \mathrm{C}-\mathrm{CH}_{2}\right]
$$$$
\mathrm{B}_{1 \mathrm{~b}}(2)\left[\mathrm{R}=\mathrm{Me} ; \mathrm{X}-\mathrm{Y}=\mathrm{H}_{2} \mathrm{C}-\mathrm{CH}_{2}\right]
$$

Avermectin $\mathrm{B}_{1 \mathrm{a}}(\mathbf{3})\left[\mathrm{R}=\mathrm{Et} ; \mathrm{X}-\mathrm{Y}=2\right.$ - $\left.{ }_{\mathrm{s}}\right]$

Avermectin $\mathrm{B}_{1 \mathrm{~b}}(4)\left[\mathrm{R}=\mathrm{Me} ; \mathrm{X}-\mathrm{Y}=2_{n}{ }_{\mathrm{N}}\right]$

Figure 1 Structure of ivermectin: mixture of dihydro derivatives of ivermectin $B_{1 a}(1)$ and $B_{1 b}(2)$ and avermectin $B_{1 a}(3)$ and $B_{1 b}(4)$.

Commercially available generic ivermectin (IVM) is an approximate 4:1 mixture of ivermectin $B_{1 a}(1)$ and $B_{1 b}$ (2), which are 22, 23-dihydro derivatives of avermectin $\mathrm{B}_{1 \mathrm{a}}(3)$ and $\mathrm{B}_{1 \mathrm{~b}}(4)$, respectively (Figure 1). ${ }^{5}$ Discovered in 1975 and marketed in 1981, ivermectin has been shown to be an extraordinary antiparasitic drug, active against a broad spectrum of organisms and widely used in veterinary medicine in 60 countries. $^{5-10}$ The compound is traditionally used to combat verminoses, ${ }^{6}$ but is also effective against most species of mites, ticks, insect larvae, and some species of head lice. It is commonly deployed as the primary parasiticide in a variety of livestock and pets and, since 1987, it has also been used for the treatment of parasitic infections in humans. Indeed, some 300 million people are taking ivermectin annually to combat two major tropical diseases, onchocerciasis and lymphatic filariasis.

In 1987, when IVM was recognized as an ideal drug to help combat onchocerciasis, it was immediately donated for treatment of the disease, under the brand name Mectizan. Soon thereafter, researchers reported that IVM showed potent molluscicidal activity against B. glabrata. $^{11}$ In 2005, a Research Collaboration was established between Brazil's Oswaldo Cruz Foundation (Fiocruz) and Japan's Kitasato Institute, where the origins of the avermectins and ivermectin lie. An initial joint project was to examine the impact of ivermectin and related compounds on Biomphalaria snails. We report herein the bioactivity of the compounds against three species of Biomphalaria species, including specimens of B. glabrata experimentally infected with S. mansoni (LE strain) parasites, with snails shedding cercariae, eggs from B. glabrata, as well as cercariae and miracidia of S. mansoni. We also report the impact of ivermectin on guppy fish (Poecilia reticulata).

\section{MATERIALS AND METHODS}

\section{Molluscs and parasites}

The snails used in this work were as follows: B. glabrata snails (originally collected from the Barreiro region, in Belo Horizonte, Minas Gerais (MG), Brazil) measuring $8-18 \mathrm{~mm}$ diameter; B. tenagophila, (descendants from specimens collected in Cabo Frio, Rio de Janeiro, Brazil) measuring 8-10 mm diameter, and B. straminea (originally from Justinopolis, MG, Brazil) measuring 4-6 mm diameter. All snails were reared at the Mollusc Room Lobato Paraense, Research Center René Rachou/FIOCRUZ, Belo Horizonte, Brazil. The snails were kept under laboratory conditions (room temperature $24-26^{\circ} \mathrm{C}$ and natural lighting) in polyethylene aquaria containing about 40 liters of water dechlorinated by means of activated charcoal filter. Ten specimens were randomly selected and used for each of the experimental groups, and similarly for the control groups. Each experimental procedure was carried out in duplicate, with all experiments being undertaken according to the guidelines of the World Health Organization. ${ }^{12}$

Egg-masses from B. glabrata were collected using uncolored polyethylene strips placed on the water surface of the aquaria. The strips where snails had deposited eggs were collected, observed under a stereomicroscope and sample masses were cut out and selected according to the following criteria: intact membranes and about 150 normal, viable eggs for each concentration with eggs in the blastula stage (i.e. 5 to $15 \mathrm{~h}$ after the first egg cleavage). ${ }^{13}$ After exposure to the test compound, a record was made of the number of dead embryos detected at each observation point, allowing a relatively easy counting of the number of eggs, the stage of embryonic development, and accurate and rapid determination of dead embryos.

Specimens of B. glabrata with a mean weight of $600 \mathrm{mg}$, were experimentally infected with $S$. mansoni (LE strain) and those shedding cercariae were exposed to different concentrations of IVM $\left(0.06-0.001 \mu \mathrm{g} \mathrm{ml}^{-1}\right)$ for $24 \mathrm{~h}$, and followed up daily for $96 \mathrm{~h}$ to observe mortality.

S. mansoni cercariae and miracidia were collected and counted under a stereomicroscope (100 cercariae or miracidia for each concentration). These were placed in Petri dishes, together with the IVM solution to be tested, at concentrations of $0.1,0.2,0.3$ or $0.4 \mu \mathrm{g} \mathrm{ml}^{-1}$. In the controls, cercariae and miracidia were placed in dechlorinated water. Observations of mortality were made under a stereomicroscope at 5, 15, 30 and $60 \mathrm{~min}$.

Specimens of guppy fish (P. reticulata), purchased at the Central Market in Belo Horizonte, after a 7-day period of adaptation in aquaria in the Mollusc Room, were exposed to IVM concentrations of $1.0,0.5$ and $0.1 \mu \mathrm{g} \mathrm{ml}^{-1}$ (10 specimens/concentration), simultaneously alongside an untreated control group.

All experiments were performed in duplicate. The values listed in this report are the mean of the duplicate experiments.

\section{Chemicals}

The ivermectin (IVM) used was a Brazilian generic product, Neoquímica. Suspensions were prepared starting from $50 \mathrm{mg}$ of the chemical diluted into $500 \mathrm{ml}$ of dechlorinated water $\left(100 \mu \mathrm{g} \mathrm{ml}^{-1}\right.$ suspension). All other concentrations were prepared via dilution of this parent solution. IVM was used at different concentrations in the experimental groups, varying between 100 and $0.001 \mu \mathrm{g} \mathrm{ml}^{-1}$, following on from pilot experiments performed with IVM at concentrations of 100,50 and $10 \mu \mathrm{g} \mathrm{ml}^{-1}$.

Two specific separate analog compounds, ivermectin $B_{1 a}(1)$ and $B_{1 b}(2)$, were prepared in Kitasato University from avermectin $B_{1 a}(3)$ and $B_{1 b}(4)$ (both obtained from cultured Streptomyces avermectinius ${ }^{14}$ ) by chemoselective hydrogenolysis. ${ }^{15}$

Avermectins 3 and 4 were separated by HPLC on a Pegasil ODS SP100 column (20 i.d. $\times 250 \mathrm{~mm}$; Senshu Scientific, Tokyo, Japan $)$ and elution with $80 \% \mathrm{CH}_{3} \mathrm{CN}$ plus $0.05 \%$ formic acid at $8.0 \mathrm{ml} \mathrm{min}^{-1}$, monitoring at $\mathrm{UV}$ $254 \mathrm{~nm}$. The peaks at retention time of around $20 \mathrm{~min}$ for 4 and $25 \mathrm{~min}$ for 3 were collected, respectively.

Ivermectins 1 and 2 and avermectins 3 and 4 were diluted in dechlorinated water and tested at differing concentrations.

\section{Experimental procedure}

The specimens of snails and fish were kept in $250 \mathrm{ml}$ glass beakers throughout the experiment, and the egg-masses in Petri dishes with $50 \mathrm{ml}$ dechlorinated water. The experimental groups remained in contact with ivermectin diluted in dechlorinated water for $24 \mathrm{~h}$. After this period, the organisms were removed, washed in running dechlorinated water and maintained in dechlorinated water for 4 days after exposure. The water was changed daily, while any dead snails, fish and embryos were removed and numbers recorded. The remaining living snails were fed fresh lettuce, and the fish with commercial feed (ProFish). The 
egg-masses were observed under a stereomicroscope, with all surviving embryos remaining under observation until eclosion.

\section{Mortality}

Retraction of the snails into their shells or hemolymph release was the criteria used to determine snail death. Temperature and $\mathrm{pH}$ of the various tested concentrations for adult snails, as well as of egg-masses and fish, were measured at the beginning and end of each test. Temperatures ranged between 25 and $26^{\circ} \mathrm{C}$ and $\mathrm{pH}$ ranged from 6.1 to 7.0 .

Calculation of the lethal concentrations, $\mathrm{LD}_{50}$ and $\mathrm{LD}_{90}$, for snails infected or not infected, using the program Graph-Pad Prism 4.0 was carried out according to the mortality rates obtained after a 96-hour period. The experiments has been repeat twice, $\mathrm{LD}_{50}$ and $\mathrm{LD}_{90}$ of each experiment were calculated by simple linear regression and Studentś $t$-test. The significance level was determined considering $P \leqslant 0.05$ as the confidence level.

\section{RESULTS}

Commercial ivermectin (IVM) killed $100 \%$ of B. glabrata snails within the first $24 \mathrm{~h}$ after initial exposure, at a concentration of $100 \mu \mathrm{g} \mathrm{ml} l^{-1}$, and after $48 \mathrm{~h}$ at 50 and $10 \mu \mathrm{g} \mathrm{ml}^{-1}$ concentrations. With reference to these specific concentrations, there was no apparent impact on B. glabrata egg masses, all intact eggs hatching normally until the end of the experiment.

As can be seen in Table 1 , at a concentration of $1.0 \mu \mathrm{g} \mathrm{ml}^{-1}$, all B. glabrata died within $48 \mathrm{~h}$, whereas B. tenagophila and B. straminea were less affected, showing 100 and $90 \%$ mortality after $96 \mathrm{~h}$, respectively. At a concentration of $0.5 \mu \mathrm{g} \mathrm{ml}^{-1}$, all B. glabrata were found to be dead within $72 \mathrm{~h}$, while $90 \%$ of B. tenagophila and $80 \%$ of B. straminea were dead after $96 \mathrm{~h}$. At a concentration of $0.3 \mu \mathrm{g} \mathrm{ml}{ }^{-1}$, a mortality rate of $90 \%$ after a period of $96 \mathrm{~h}$ was detected for both B. glabrata and B. tenagophila, and $70 \%$ for B. straminea. The mortality difference among the three species was not significant $(P=0.14)$ (Table 1). The calculated lethal doses were: $\mathrm{LD}_{50}=0.03 \mu \mathrm{g} \mathrm{ml}^{-1}$ and $\mathrm{LD}_{90}=0.3 \mu \mathrm{g} \mathrm{ml}^{-1}$ for $B$. glabrata and B. tenagophila, respectively, plus $\mathrm{LD}_{50}=0.13 \mu \mathrm{g} \mathrm{ml}^{-1}$ and $\mathrm{LD}_{90}=1.0 \mu \mathrm{g} \mathrm{ml}^{-1}$ for B. straminea.

Table 1 Molluscicidal activity of commercial ivermectin (a mixture of ivermectin $B_{1 a}(1)$ and $B_{1 b}(2)$ ) against $B$. glabrata, $B$. tenagophila and $B$. straminea

\begin{tabular}{|c|c|c|c|c|c|}
\hline \multirow[b]{3}{*}{ Species $^{\mathrm{a}}$} & \multirow[b]{3}{*}{ Concentration ( $\mu \mathrm{g} \mathrm{ml}^{-1}$ ) } & \multicolumn{4}{|c|}{ Mortality $(\%)^{b}$} \\
\hline & & \multicolumn{4}{|c|}{ Time (h) } \\
\hline & & 24 & 48 & 72 & 96 \\
\hline \multirow[t]{4}{*}{ B. glabrata } & 1.0 & 60 & 100 & & \\
\hline & 0.5 & 20 & 90 & 100 & \\
\hline & 0.3 & 0 & 80 & 90 & 90 \\
\hline & Control & 0 & 0 & 0 & 0 \\
\hline \multirow[t]{4}{*}{ B. tenagophila } & 1.0 & 10 & 60 & 90 & 100 \\
\hline & 0.5 & 0 & 70 & 90 & 90 \\
\hline & 0.3 & 0 & 60 & 80 & 90 \\
\hline & Control & 0 & 0 & 0 & 0 \\
\hline \multirow[t]{4}{*}{ B. straminea } & 1.0 & 20 & 70 & 80 & 90 \\
\hline & 0.5 & 0 & 70 & 80 & 80 \\
\hline & 0.3 & 0 & 40 & 60 & 70 \\
\hline & Control & 0 & 0 & 0 & 0 \\
\hline
\end{tabular}

aDiameter of the specimens used in this work. B. glabrata: $8-10 \mathrm{~mm}$; B. tenagophila: 8-10 mm; B. straminea: 4-6 mm.

${ }^{\mathrm{b}}$ The results are the mean of experiments performed in duplicate.
As can be seen in Table 2, snails infected with S. mansoni parasites exhibited $100 \%$ mortality within $24 \mathrm{~h}$ at an IVM concentration of $0.3 \mu \mathrm{g} \mathrm{ml}^{-1}$. At $0.03 \mu \mathrm{g} \mathrm{ml}^{-1}$, complete mortality was seen after $72 \mathrm{~h}$ post-exposure. After $48 \mathrm{~h}$ at a concentration of $0.01 \mu \mathrm{g} \mathrm{ml}^{-1}$, mortality was $100 \%$, the figure being $70 \%$ at a concentration of $0.005 \mu \mathrm{g} \mathrm{ml} l^{-1}$ and $30 \%$ at $0.001 \mu \mathrm{g} \mathrm{ml}^{-1}$. The IVM tested and found to be effective appeared to be significantly more potent against infected snails than against uninfected molluscs. The $\mathrm{LD}_{50}$ of IVM for infected snails was $0.002 \mu \mathrm{g} \mathrm{ml}^{-1}$ and $0.006 \mu \mathrm{g} \mathrm{ml}^{-1}$ for the $\mathrm{LD}_{90}$ value, whereas the figures for uninfected snails were an $\mathrm{LD}_{50}=0.03 \mu \mathrm{g} \mathrm{ml}^{-1}$ and $\mathrm{LD}_{90}=0.3 \mu \mathrm{g} \mathrm{ml}^{-1}$, respectively (Table 3). Potentiation of molluscicidal activity shown against $B$. glabrata infected with $S$. mansoni compared with uninfected snails was statistically significant.

Ivermectin $\mathrm{B}_{1 \mathrm{a}}(\mathbf{1})$, the major component of IVM, was inactive at a concentration of $0.3 \mu \mathrm{g} \mathrm{ml}^{-1}$, whereas in the case of the minor component, ivermectin $\mathrm{B}_{1 \mathrm{~b}}(2)$, the same concentration produced $100 \%$ mortality of snails, although it did not show statistical significance when comparing the results presented by infected and uninfected snails at the concentrations tested. The related natural products, avermectin $\mathrm{B}_{1 \mathrm{a}}(3)$ and avermectin $\mathrm{B}_{1 \mathrm{~b}}(4)$ demonstrated no molluscicidal activity at a concentration of $0.3 \mu \mathrm{g} \mathrm{ml}^{-1}$ (Table 3).

The efficacy of IVM against S. mansoni parasites was also evaluated, with $50 \%$ of miracidia and cercariae dying within $5 \mathrm{~min}$ of first contact with the chemical at a concentration of $0.2 \mu \mathrm{g} \mathrm{ml}^{-1}$. After $30 \mathrm{~min}$ of exposure, mortality was around $90 \%$, rising to $100 \%$ after 60 min (data not shown)

The piscicidal activity of ivermectin was examined and, with respect to guppy fish (P. reticulata), $100 \%$ of specimens died within the first 24-h following exposure to concentrations of 1.0 and $0.5 \mu \mathrm{g} \mathrm{ml}^{-1}$, while $30 \%$ of fish died within 48-hour after exposure to a concentration of $0.01 \mu \mathrm{g} \mathrm{ml}^{-1}$, with values of 0.03 and $0.1 \mu \mathrm{g} \mathrm{ml}^{-1}$ for the $\mathrm{LD}_{50}$ and $\mathrm{LD}_{90}$, respectively (Table 4 ).

\section{DISCUSSION}

The WHO recommends niclosamide as the standard molluscicide to combat schistosomiasis intermediate host snails. A concentration of $1.0 \mu \mathrm{g} \mathrm{ml}^{-1}$ causes $100 \%$ mortality in B. glabrata within $8 \mathrm{~h}^{13}$ and a concentration of $0.14 \mu \mathrm{g} \mathrm{ml}^{-1}$ causes $100 \%$ mortality for egg-masses after 24 -h of contact, ${ }^{16}$ while the lethal concentration for fish is $0.2 \mu \mathrm{g} \mathrm{ml}^{-1} .{ }^{17}$ Schistosome miracidia are killed by niclosamide at a concentration of $0.3 \mu \mathrm{g} \mathrm{ml}^{-1}$ in minutes, and $0.1 \mu \mathrm{g} \mathrm{ml}^{-1}$ if the exposure is longer, ${ }^{18}$ while cercariae are affected by concentrations of $0.1-0.2 \mu \mathrm{g} \mathrm{ml}^{-1}$. However, niclosamide is far from an ideal molluscicide due to its various adverse effects and there is an urgent need for safe and effective alternatives.

Matha and Weiser were the first to report the molluscicidal activity of ivermectin, under laboratory conditions, against B. glabrata. They found that snails were highly susceptible to ivermectin in low concentrations: $\mathrm{LC}_{50}=0.03 \mu \mathrm{g} \mathrm{ml}^{-1}, \mathrm{LC}_{90}=0.042 \mu \mathrm{g} \mathrm{ml}^{-1}$, and $\mathrm{LC}_{100}=0.055 \mu \mathrm{g} \mathrm{ml}^{-1} 12$ to $24 \mathrm{~h}$ after treatment. ${ }^{11}$ They concluded that ivermectin was 60 to 120 times more toxic to B. glabrata than trifenmorph or niclosamide. Research in Africa also concluded that ivermectin killed various intermediate host snails, including B. pfeifferi, with an $\mathrm{LC}_{50}$ value of $0.71 \mu \mathrm{g} \mathrm{ml}^{-1}$. Moreover, sub-lethal concentrations $\left(0.01 \mu \mathrm{g} \mathrm{ml}^{-1}\right)$ led to considerable decreases in the number of eggs laid by the exposed snails. ${ }^{19}$ Our study confirms that ivermectin is an effective molluscicide, killing $B$. glabrata, $B$. tenagophila and B. straminea, with $\mathrm{LD}_{90}$ of $0.3 \mu \mathrm{g} \mathrm{ml}^{-1}$ for the first two species, and $1.0 \mu \mathrm{g} \mathrm{ml}^{-1}$ for B. straminea. B. straminea is less susceptible to S. mansoni infection than B. glabrata end B. tenagophila in Brazil. Compatibility Index assessments using three strains of $S$. mansoni 
Table 2 Molluscicidal activity on B. glabrata snails ${ }^{a}$ of commercial ivermectin (IVM) - a mixture of ivermectin $B_{1 a}$ (1) and $B_{1 b}$ (2), 1 and 2 alone, avermectin $B_{1 a}(3)$ and $B_{1 b}(4)$

\begin{tabular}{|c|c|c|c|c|c|c|c|c|c|}
\hline \multirow[b]{4}{*}{ Compound } & \multirow{4}{*}{$\begin{array}{c}\text { Concentration } \\
\left(\mu g \mathrm{ml}^{-1}\right)\end{array}$} & \multicolumn{8}{|c|}{ Mortality $(\%)^{b}$} \\
\hline & & \multicolumn{4}{|c|}{ Snails without infection } & \multicolumn{4}{|c|}{ Snails shedding cercariae } \\
\hline & & \multicolumn{4}{|c|}{ After exposure (h) } & \multicolumn{4}{|c|}{ After exposure (h) } \\
\hline & & 24 & 48 & 72 & 96 & 24 & 48 & 72 & 96 \\
\hline \multirow[t]{5}{*}{ IVM } & 0.3 & 80 & 100 & & & 100 & & & \\
\hline & 0.03 & 0 & 10 & 40 & 70 & 0 & 50 & 100 & \\
\hline & 0.01 & 10 & 20 & 40 & 40 & 50 & 100 & & \\
\hline & 0.005 & 10 & 10 & 30 & 30 & 50 & 70 & 70 & 70 \\
\hline & 0.001 & 0 & 10 & 20 & 20 & 30 & 30 & 30 & 30 \\
\hline 1 & 0.3 & 0 & 0 & 0 & 0 & 0 & 0 & 0 & 0 \\
\hline 2 & 0.03 & 20 & 100 & & & 40 & 100 & & \\
\hline 3 & 0.3 & 0 & 0 & 0 & 0 & 0 & 0 & 0 & 0 \\
\hline 4 & 0.3 & 0 & 0 & 0 & 0 & 0 & 0 & 0 & 0 \\
\hline Control & - & 0 & 0 & 0 & 0 & 0 & 0 & 0 & 10 \\
\hline
\end{tabular}

Snails diameter: $10-18 \mathrm{~mm}$

${ }^{\mathrm{b}}$ Mean of experiments performed in duplicate.

(LE, SJ and AL) demonstrating that $B$. straminea displays by far the lowest levels of infection. ${ }^{20}$

We found ivermectin to be less potent than previously reported, B. glabrata appearing 5-fold less susceptible to ivermectin in comparison with the data presented by Matha and Weiser. It is therefore important to emphasize our finding that only one of the two constituents of IVM appears to have molluscicidal properties. Ivermectin $\mathrm{B}_{1 \mathrm{~b}}$ (2) kills snails, while ivermectin $\mathrm{B}_{1 \mathrm{a}}$ (1) does not demonstrate such activity. The two chemicals are extremely similar, the only difference being that ivermectin $\mathrm{B}_{1 \mathrm{a}}$ has an ethyl group at the C-26 position whereas ivermectin $B_{1 b}$ has a methyl group at the C-26 position. Thus the presence of the methyl group at the $\mathrm{C}-26$ position in 2 which appears to be crucial to confer the molluscicidal property. The compound 'ivermectin' is routinely recognized as being a mixture containing $80 \%$ of 1 and $20 \%$ of 2 . However, there is significant variance, with several authorities using slightly different specifications, the UN Food and Agriculture Organization (FAO) defining ivermectin as containing 'no less than $80 \%$ ' of 1 and 'no more than $20 \%$ ' of 2 (http://www.fao.org/fileadmin/user_upload/vetdrug/docs/41-3-ivermectin. pdf) while Merck, the original manufacturer of ivermectin, defined it as being composed of 'at least $80 \%$ ' of 1 and 'not more than $20 \%$ ' of $2 .{ }^{21}$ Such possible minute variations, which could lead to differing amounts of the molluscicidal minor component 2 in commercially available products, might account for differences in the potency of IVM tested against snails by different researchers.

IVM did not act on egg masses from B. glabrata, even at the highest concentration used (that is, $100 \mu \mathrm{g} \mathrm{ml}^{-1}$ ). This low susceptibility of egg masses to chemical attack has already been reported. ${ }^{22-24}$ The high degree of resistance to molluscicides shown by parasite egg masses is probably due to the high molecular weights of these substances, which prevents them from penetrating the gelatinous membrane of the egg masses. ${ }^{25}$ However, IVM did prove to be piscicidal, producing $100 \%$ mortality at a concentration of $0.5 \mu \mathrm{g} \mathrm{ml}^{-1}$ when tested on guppy fish, with an $\mathrm{LD}_{90}$ value of $0.1 \mu \mathrm{g} \mathrm{ml}^{-1}$.
Table $3 \mathrm{LD}_{50}$ and $\mathrm{LD}_{90}$ of commercial ivermectin-a mixture of ivermectin $B_{1 a}(1)$ and $B_{1 b}(2)$, and 2 alone against $B$. glabrata snails

\begin{tabular}{llllll}
\hline & \multicolumn{2}{c}{ Ivermectin } & & \multicolumn{2}{l}{ Ivermectin $B_{1 b}$ (2) } \\
\cline { 2 - 3 } & $L D_{50}$ & $L D_{90}$ & & $L D_{50}$ & $L D_{90}$ \\
\hline Organism & 0.03 & 0.3 & & 0.007 & 0.009 \\
Snails without infection & 0.002 & 0.006 & & 0.001 & 0.008 \\
\hline
\end{tabular}

Table 4 Piscicidal activity on guppy fish (Poecilia reticulata) of commercially available ivermectin

\begin{tabular}{|c|c|c|c|c|}
\hline \multirow[b]{3}{*}{ Concentration $\left(\mu \mathrm{g} \mathrm{ml}^{-1}\right)$} & \multicolumn{4}{|c|}{ Mortality (\%)a } \\
\hline & \multicolumn{4}{|c|}{ Time after exposure (h) } \\
\hline & 24 & 48 & 72 & 96 \\
\hline 1.0 & 100 & & & \\
\hline 0.5 & 100 & & & \\
\hline 0.1 & 70 & 70 & 80 & 90 \\
\hline 0.01 & 0 & 30 & 30 & 30 \\
\hline Control & 0 & 0 & 0 & 0 \\
\hline
\end{tabular}

The results are the mean of experiments performed in duplicate.

One very important and highly significant finding to emerge from this work is that B. glabrata snails that were shedding S. mansoni cercariae were more susceptible to IVM, with $100 \%$ mortality at a concentration of $0.01 \mu \mathrm{g} \mathrm{ml}^{-1}$. It is notable that this concentration, which is fatal for infected snails, kills only $30 \%$ of fish. In relation to $\mathrm{LD}_{90}$, specimens of $B$. glabrata shedding cercariae died when a concentration much lower than that required to kill the uninfected specimens was used. A similar finding has previously been reported, Bulinus truncatus snails infected with $S$. haematobium, at the elimination phase of cercariae or in the pre-patent stage, being more susceptible to niclosamide than those uninfected. ${ }^{26}$ The presence of S. mansoni infection in the snail induced a devastating effect on the several organs, specially on the hepatopancreas gland. This organ is the main responsible for the snail metabolism. It is possible that this is the reason for the higher mortality of infected snails.

In conclusion, this study confirmed that ivermectin is an effective molluscicide, killing adult B. glabrata snails at a concentration lower than that seen with the commonly used niclosamide. Furthermore, it is even more active against snails infected with $S$. mansoni parasites. The work also confirmed that the actual bioactive component is ivermectin $\mathrm{B}_{1 \mathrm{~b}}$, the minor component of the commercially available chemical. Probably the dose used was too high to allow selectivity action between infected or normal snails. Although ivermectin showed no impact on egg-masses, it proved to display moderate piscicidal activity at concentrations lethal for infected snails.

It is well-known that ivermectin can be toxic to non-target invertebrates, such as insects, that it remains active in the environment for a comparatively long time, and that repeated applications of the product in an aquatic environment needs much more in-depth research to ascertain its true impact on non-target aquatic organisms. However, taking into account the low dose required to kill $100 \%$ of shedding cercariae snails $\left(0.01 \mu \mathrm{g} \mathrm{ml}^{-1}\right)$, our results support the belief that there is significant scope to explore the use of ivermectin and its derivatives, particularly ivermectin $B_{1 b}$, for the future development of 
a safe, effective and much needed tool to help with global efforts to control the transmission of schistosomiasis.

\section{CONFLICT OF INTEREST}

The authors declare no conflict of interest.

\section{ACKNOWLEDGEMENTS}

We would like to express our thanks to Sueleny Silva Teixeira Ferreira, of the Mollusc Room Lobato Paraense, Research Center René Rachou/FIOCRUZ, for technical support during the experiments, Dr John Kusel for help with the preparation of this manuscript and to Dr Andy Crump to check the grammar and to clarify the logic of the manuscript. This work was funded by the Department of Science and Technology (DECIT), Ministry of Health (FIOTEC nos 439 and 820); National Council for Scientific and Technological Development (CNPq), Ministry of Science and Technology (nos 573642/2008-7 and IA Productivity Fellowship to CMM); Ministry of Education/CAPES (nos 573642/2008-7); Research Foundation of the State of Rio de Janeiro (FAPERJ) (nos 573642/2008-7 and Oswaldo Cruz Foundation (Fiocruz). The funders had no role in study design, data collection and analysis, decision to publish, or preparation of the manuscript.

1 Katz, N. \& Peixoto, S. V. Critical analysis of the estimated number of Schistosomiasis mansoni carriers in Brazil. Rev. Soc. Bras. Med. Trop. 33, 303-308 (2000).

2 Clumpp, R. K., Slootweg, R. in Vector Control-Method for use by individuals and communities (ed. Rozendaal, J. A.) 337-356 (World Health Organization, Geneva, Switzerland, 1997).

3 Clark, T. E., Appleton, C. C. \& Drewes, S. E. A semi-quantitative approach to the selection of appropriate candidate plant molluscicides-A South African application. J. Ethnopharmacol. 56, 1-13 (1997).

4 Oliveira-Filho, E. C. \& Paumgartten, F. J. R. Toxicity of Euphorbia milii latex and niclosamide to snails and non-target aquatic species. Ecotoxicol. Environ. Saf. 46, 342-350 (2000).

5 Zaha, O., Hirata, T., Kinjo, F., Saito, A. Macrolide Antibiotics-Chemistry, Biology and Practice 2nd edn (ed. Ōmura, S.) 403-419 (Academic Press, Amsterdam and Boston, USA, 2002).

6 Cupp, E. W. et al. The effects of ivermectin on transmission of Onchocerca volvulus. Science 231, 740-742 (1986).
7 Greene, B. M., Brown, K. R., Taylor, H. R. in Ivermectin and abamectin (ed. Campbell, W. C.) 311-323 (Springer Verlag, New York, USA, 1989).

8 Crump, A. \& Ōmura, S. Ivermectin, 'Wonder drug' from Japan: the human use perspective. Proc. Jpn Acad. Ser. B 87, 13-28 (2011).

9 Ōmura, S. Ivermectin: 25 years and still going strong. Int. J. Antimicrob. Agents 31, 91-98 (2008).

10 Ōmura, S. \& Crump, A. The life and times of ivermectin: A success story. Nature Rev. Microbiol. 2, 984-989 (2004).

11 Matha, V. \& Weiser, J. Molluscicidal effect of ivermectin on Biomphalaria glabrata. J. Invertebr. Pathol. 52, 354-355 (1988).

12 World Health Organization. Molluscicide screening and evaluation. Bull World Health Organ. 33, 567-581 (1965).

13 Oliver, L. The Employment of Snail Eggs for Chemical Tests (Working paper WHO/ Bilharziasis, Geneva, Switzerland, 1960).

14 Burg, R. W. et al. Avermectins, new family of potent anthelmintic agents: Producing organism and fermentation. Antimicrob. Agents Chemother. 15, 361-367 (1979).

15 Chabala, J. C. et al. Ivermectin, a new broad-spectrum antiparasitic agent. J. Med. Chem. 23, 1134-1136 (1980).

16 Ritchie, L. S., Bermos-Duran, L. A., Frick, L. P. \& Fox, I. Molluscicidal qualities of Bayluscide (Bayer 73) revealed by 6-hour and 24-hour exposures against representative stages and sizes of Australorbis glabratus. Bull. World Health Organ. 29, 281-286 (1963).

17 Harrison, A. D. \& Rattray, E. A. Biological effects of mollusciciding natural waters. S. Afr. J. Sci. 62, 238-241 (1966).

18 Gönnert, R. \& Strufe, D. R. Comparative investigations of some molluscicides. Ciba Foundation Symposium on Bilharziasis 326-338 (J \& A Churchill, London, UK, 1962).

19 Okafor, F. C. On the effects of ivermectin on freshwater snails of medical and veterinary importance. Angew. Parasitol. 31, 65-68 (1990).

20 Souza, C. P., Jannotti-Passos, L. K. \& Freitas, J. R. Degree of host-parasite compatibility between Schistosoma mansoni and their intermediate molluscan hosts in Brazil. Mem. Inst. Oswaldo Cruz 90, 5-10 (1995).

21 Campbell, W. C. Ivermectin: an update. Parasitol. Today 1, 10-16 (1985).

22 Lemma, A., Brody, G., Newell, G. W., Parkhurst, R. M. \& Skinner, W. A. Studies on the molluscicidal properties of endod (Phytolacca dodecandra): I. Increased potency with butanol extraction. J. Parasitol. 58, 104-107 (1972).

23 Rouquayrol, M. Z., Souza, M. P. \& Matos, F. J. A. Atividade moluscicida de Pithecelobium multiflorum. Rev. Soc. Bras. Med. Trop. 7, 11-19 (1973).

24 Pereira, J. P., Souza, C. P. \& Mendes, N. M. Propriedades molluscicidas da Euphorbia cotinifolia L. Rev. Bras. Pesq. Med. Biol. 11, 345-351 (1978).

25 Lemma, A. \& Yau, P. Studies on the molluscicidal properties of endod (Phytolacca dodecandra), II. Comparative toxicity of various molluscicides to fish and snails. Ethiop. Med. J. 12, 109-114 (1974).

26 Massoud, J., Arfaa, F. \& Chu, K. Y. Effect of Bayluscide (Bayer 73) on the development of Schistosoma haematobium in Bulinus truncatus. Bull Soc. Pathol. Exot. 66, 544-547 (1973). 